\title{
Physical and Electrochemical Properties of 1-ethyl-3-methylimidazolium Ionic Liquids of Mixed Anions, $(\mathrm{FH})_{n} \mathrm{~F}^{-}, \mathrm{BF}_{4}^{-}$, and $\mathrm{N}\left(\mathrm{SO}_{2} \mathrm{CF}_{3}\right)_{2}^{-}$
}

\author{
Junya Ohtsuki, Kazuhiko Matsumoto, and Rika Hagiwara* \\ Graduate School of Energy Science, Kyoto University (Yoshida, Sakyo-ku, Kyoto 606-8501, Japan) \\ Received February 12, 2009 ; Accepted June 11, 2009

\begin{abstract}
Physical and electrochemical properties of 1-ethyl-3-methylimidazolium ionic liquids of mixed anions, $(\mathrm{FH})_{2.3} \mathrm{~F}^{-}, \mathrm{BF}_{4}^{-}$, and $\mathrm{N}\left(\mathrm{SO}_{2} \mathrm{CF}_{3}\right)_{2}$, have been investigated. Molar volume shows almost linear behavior, whereas molar conductivity is decreased by mixing for the systems involving $(\mathrm{FH})_{2.3} \mathrm{~F}^{-}$due to the enhancement of ion association in spite of the decrease in viscosity. The currents at the anode and cathode limits in the cyclic voltammogram of $\mathrm{EMIm}(\mathrm{FH})_{2.3} \mathrm{~F}$ decreases with decrease in the molar ratio of $(\mathrm{FH})_{n} \mathrm{~F}^{-}$, suggesting the involvement of $(\mathrm{FH})_{n} \mathrm{~F}^{-}$for both electrode reactions. Electrochemical stability of the $\mathrm{BF}_{4}-\mathrm{TFSA}$ mixture is unchanged by mixing.
\end{abstract}

Key Words : Ionic Liquid, Molten Salt, Mixed Ionic Liquids, Conductivity

\section{Introduction}

Room temperature ionic liquids (RTILs) are now widely studied as potential electrolytes for energy storage devices and plating, as well as media for extraction and separation processes, organic syntheses, and catalysis. ${ }^{1-4)}$ Most alkylimidazolium based RTILs are versatile and widely used due to their favorable characteristics such as low vapor pressure, wide liquid-phase temperature range, nonflammability, and high electrochemical stability. Physical properties of RTILs are changed by the combination of cationic and anionic structures. The tetrafluoroborate $\left(\mathrm{BF}_{4}^{-}\right)$and bis(trifluoromethylsulfonyl)

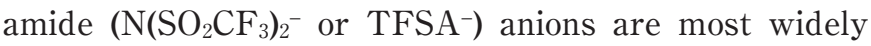
used for syntheses of RTILs owing to their abilities to form low melting salts with high conductivity. ${ }^{5-7}$ ) Fluorohydrogenate anion $\left((\mathrm{FH})_{n} \mathrm{~F}^{-}\right)$also forms RTILs combined with a variety of heterocyclic ammonium cations, exhibiting remarkably high ionic conductivities. ${ }^{89)}$ The vacuum-stable $\mathrm{HF}$ composition, $n$, for $(\mathrm{FH})_{n} \mathrm{~F}^{-}$ in the fluorohydrogenate RTILs based on the heterocyclic ammonium cations depends on the temperature, giving $n=2.3$ at $25{ }^{\circ} \mathrm{C}$ regardless of the cationic structure. ${ }^{10)}$ The anions of the vacuum stable fluorohydrogenate RTILs at $25{ }^{\circ} \mathrm{C}$ are regarded as a mixture of $(\mathrm{FH})_{2} \mathrm{~F}^{-}$and $(\mathrm{FH})_{3} \mathrm{~F}^{-}$.

In previous reports, mixing of RTILs was examined for several systems to improve the physical or chemical properties as electrolytes. ${ }^{11)}$ This communication reports the physical and electrochemical properties of 1-ethyl-3methylimidazolium (EMIm) ionic liquids of mixed anions, $(\mathrm{FH})_{2.3} \mathrm{~F}^{-}, \mathrm{BF}_{4}^{-}$, and $\mathrm{N}\left(\mathrm{SO}_{2} \mathrm{CF}_{3}\right)_{2}$.

\section{Experimental}

All the nonvolatile materials were handled in the dry Ar atmosphere of a glovebox. Room temperature ionic liquids, EMIm $(\mathrm{FH})_{2.3} \mathrm{~F}^{8)}$ and EMImTFSA, ${ }^{6)}$ were prepared according to the literature method. The tetrafluoroborate salt, $\mathrm{EMImBF}_{4}$, was used as purchased (Kanto Kagaku Co., Inc.). Physical and electrochemical properties were measured as previously reported. ${ }^{9)}$

\section{Results and Discussion}

Physical properties of neat $\operatorname{EMIm}(\mathrm{FH})_{2.3} \mathrm{~F}, \mathrm{EMImBF}_{4}$, and EMImTFSI are listed in Table 1. The values obtained for $\mathrm{EMImBF}_{4}$ and EMImTFSI agree well with those previously reported.-7) Physical properties of EMIm ionic liquids of the mixed anions are shown in Fig. 1.

\section{1 Density and molar volume}

Density of the $(\mathrm{FH})_{2.3} \mathrm{~F}-\mathrm{BF}_{4}$ system shows a linear relationship with $x\left((\mathrm{FH})_{2.3} \mathrm{~F}\right)$, whereas those of the other two systems involving TFSA- show convex curvatures. Since the formula weight of EMImTFSA (391.3) is significantly larger than those of EMIm(FH) ${ }_{2.3} \mathrm{~F}(176.2)$ and $\mathrm{EMImBF}_{4}$ (198.0), the contribution of EMImTFSA to the weight in the mixture is larger than the other salts, resulting in the increase in the apparent density with respect to the

Table 1 Physical properties ${ }^{a}$ of neat $\operatorname{EMIm}(\mathrm{FH})_{2.3} \mathrm{~F}, \mathrm{EMImBF}_{4}$, and $\mathrm{EMImTFSA}$

\begin{tabular}{|c|c|c|c|c|c|c|c|}
\hline & $\begin{array}{l}T_{m} \\
/ \mathrm{K}\end{array}$ & $\begin{array}{c}T_{g} \\
/ \mathrm{K}\end{array}$ & $\begin{array}{c}\rho \\
/ \mathrm{g} \mathrm{cm}^{-3}\end{array}$ & $\begin{array}{c}M . V . \\
/ \mathrm{cm}^{3} \mathrm{~mol}^{-1}\end{array}$ & $\begin{array}{c}\sigma \\
/ \mathrm{mS} \mathrm{cm}^{-1}\end{array}$ & $\begin{array}{c}\Lambda \\
/ \mathrm{S} \mathrm{cm}^{2} \mathrm{~mol}^{-1}\end{array}$ & $\begin{array}{c}\eta \\
/ \mathrm{cP}\end{array}$ \\
\hline $\mathrm{EMIm}(\mathrm{FH})_{2.3} \mathrm{~F}^{b}$ & 208 & 148 & 1.13 & 155.9 & 100 & 15.8 & 4.9 \\
\hline $\mathrm{EMImBF}_{4}$ & 288 & 194 & 1.27 & 155.9 & 13.0 & 2.02 & 34 \\
\hline EMImTFSA & 254 & - & 1.51 & 259.3 & 7.6 & 1.98 & 31 \\
\hline
\end{tabular}

${ }^{a} T_{m}$ : melting point, $T_{g}$ : glass transition point, $\rho$ : density at $298 \mathrm{~K}$, M.V.: molar volume at $298 \mathrm{~K}$, $\sigma$ : conductivity at $298 \mathrm{~K}$ $\Lambda$ : molar conductivity at $298 \mathrm{~K}, \eta$ : viscosity at $298 \mathrm{~K} .{ }^{b}$ Ref. 8. 

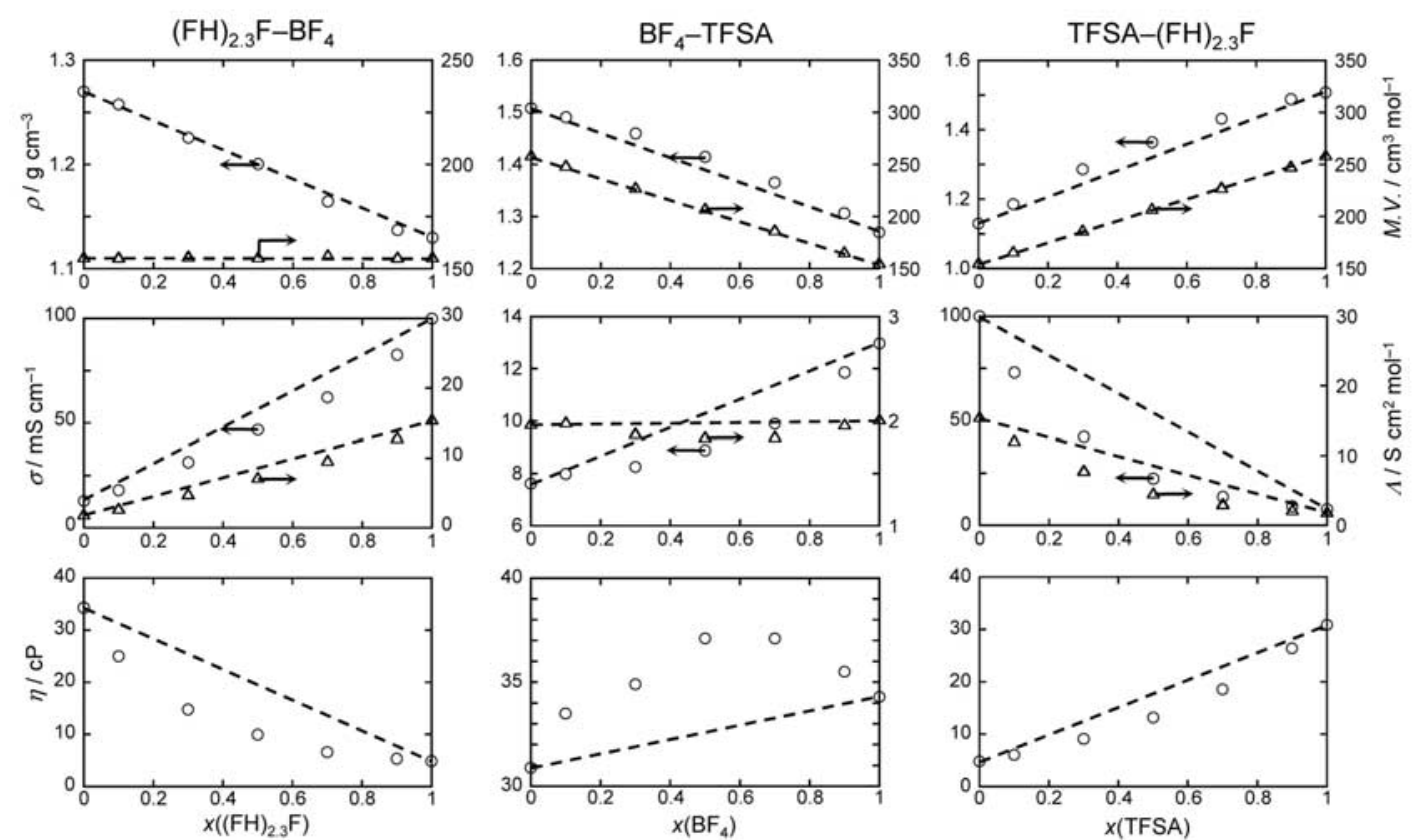

Fig. 1 Density $(\rho)$, molar volume $(M . V$.$) , conductivity (\sigma)$, molar conductivity $(\Lambda)$, and viscosity $(\eta)$ at $298 \mathrm{~K}$ for EMIm ionic liquids of the mixed anions, $(\mathrm{FH})_{2.3} \mathrm{~F}_{-}-\mathrm{BF}_{4}, \mathrm{BF}_{4}-\mathrm{TFSA}$, and TFSA- $(\mathrm{FH})_{2.3} \mathrm{~F}$.

molar ratio. The almost linear relationship is obtained in molar volume for all the mixtures, where the deviation observed for the $(\mathrm{FH})_{2.3} \mathrm{~F}-\mathrm{BF}_{4}$ system is within error. This observation indicates that there is little volume change by mixing these ionic liquids, in other words, the volume which each ion occupies in the neat ionic liquid is preserved in the mixture.

\section{2 Conductivity, molar conductivity, and viscosity}

In all the three systems, both conductivities and molar conductivities exhibit concave curvatures by mixing the anions. The largest drop of the conductivity was observed for the TFSA- $(\mathrm{FH})_{2.3} \mathrm{~F}$ system, where the conductivity of the 50:50 mixture is only $42 \%$ of the estimated value from the neat RTILs. According to the previous study, the high conductivity for fluorohydrogenate RTILs is explained by their low viscosity, leading to the large diffusion coefficients of both the cation and anion compared to the ions in other RTILs although the anion moves faster than the cation. ${ }^{12)}$ The decrease of the conductivity by mixing $\mathrm{BF}_{4}^{-}$and TFSA- is explained by the increase in viscosity as the viscosity shows the corresponding convex curvature. In the cases of the other two systems involving $(\mathrm{FH})_{n} \mathrm{~F}^{-}$, the association of the ions, that is, formation of ion pair or aggregate, is significantly enhanced by mixing the anions, since the viscosity shows concave curvatures violating Walden's rule. ${ }^{7,8,12)}$ It was reported that the molar conductivity for the EMImOSO ${ }_{2} \mathrm{CF}_{3}$-EMImTFSA system is enhanced by mixing the anions, showing a remarkably convex curvature, ${ }^{13)}$ whereas such behavior was not observed for the present cases.

\section{3 Thermal properties}

Phase behavior of the mixed ionic liquids was studied by differential scanning calorimetry (DSC) in a Ni cell under a dry $\mathrm{N}_{2}$ atmosphere at the scan rate of $10 \mathrm{~K} \mathrm{~min}^{-1}$.

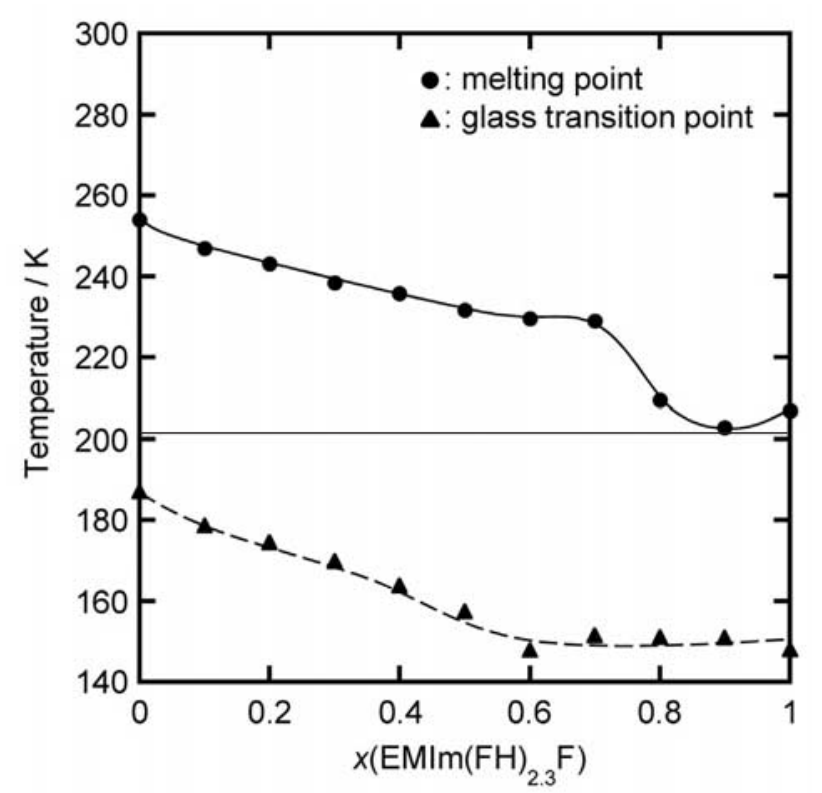

Fig. 2 Phase diagram of the EMImTFSA-EMIm(FH $)_{2.3} \mathrm{~F}$ system.

Both $\mathrm{EMIm}(\mathrm{FH})_{2.3} \mathrm{~F}$ and $\mathrm{EMImBF}_{4}$ are super-cooled to form a glass phase in the cooling process, followed by glass transition point, crystallization, and melting in the heating process. ${ }^{7.8)}$ The $(\mathrm{FH})_{2.3} \mathrm{~F}-\mathrm{BF}_{4}$ mixture does not show any exo- or endothermic peak for the entire composition range, suggesting the stable super-cooled state. Although EMImTFSA showed an exothermic peak of crystallization in the cooling process followed by the melting in the heating process, the $\mathrm{BF}_{4}^{-}$TFSA mixture does not show any exo- or endothermic peak for the entire composition range. These observations suggest 


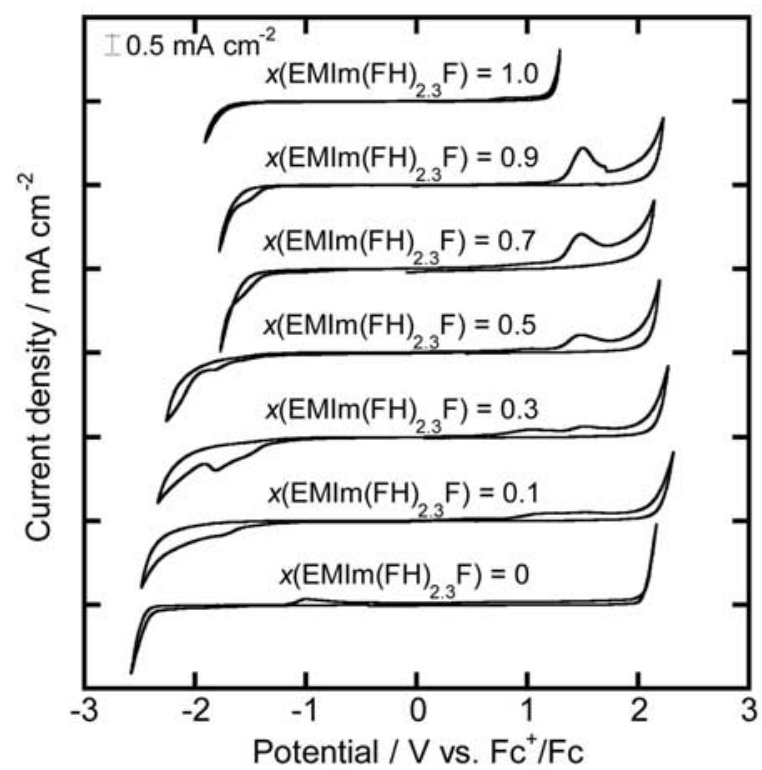

Fig. 3 Cyclic voltammograms of a glassy carbon electrode in the $\mathrm{EMIm}(\mathrm{FH})_{2.3} \mathrm{~F}-\mathrm{EMImBF}_{4}$ system. C. E. : glassy carbon, scan rate: $5 \mathrm{mV} \mathrm{s}^{-1}$. The potential was referenced to the ferrocenium/ferrocene $\left(\mathrm{Fc}^{+} / \mathrm{Fc}\right)$ redox couple in each ionic liquid.

that $\mathrm{BF}_{4}^{-}$facilitates the formation of the super-cooled state and prevent the system from crystallizing. As shown in Fig. 2, the $(\mathrm{FH})_{2.3} \mathrm{~F}$-TFSA mixture show both glass transition point and melting point in any composition. Since the mixture with a high ratio of $\operatorname{EMIm}(\mathrm{FH})_{2.3} \mathrm{~F}$ did not show a clear peak, the slow scan rate $\left(2 \mathrm{~K} \mathrm{~min}^{-1}\right)$ was applied. The glass transition point gradually decreases with increase in the molar ratio of $(\mathrm{FH})_{2.3} \mathrm{~F}^{-}$in the range of $0 \leq x\left((\mathrm{FH})_{2.3} \mathrm{~F}\right) \leq 0.6$ and becomes almost constant in the range of $0.6 \leq x\left((\mathrm{FH})_{2.3} \mathrm{~F}\right) \leq 1.0$. The eutectic point of EMIm(FH) ${ }_{2.3} \mathrm{~F}$-EMImTFSI was determined to be $203 \mathrm{~K}$ at the composition of $\mathrm{EMIm}(\mathrm{FH})_{2.3} \mathrm{~F}: \mathrm{EMImTFSI}=90: 10$. The abrupt drop in melting point between $0.7 \leq$ $x\left((\mathrm{FH})_{2.3} \mathrm{~F}\right) \leq 0.8$ may arise from a significant structural change in this region.

Thermal decomposition was examined by thermogravimetric analysis (TGA) in a $\mathrm{Ni}$ cell under a dry $\mathrm{N}_{2}$ atmosphere at the scan rate of $10 \mathrm{~K} \mathrm{~min}$. The neat $\mathrm{EMIm}(\mathrm{FH})_{2.3} \mathrm{~F}$ slowly loses $\mathrm{HF}$ at elevated temperatures and decomposes around $550 \mathrm{~K}$, whereas $\mathrm{EMImBF}_{4}$ and EMImTFSA have higher thermal stabilities up to about $650 \mathrm{~K}$ and $700 \mathrm{~K}$, respectively. Thermogravimetric analysis revealed that thermal decomposition of the component in the $(\mathrm{FH})_{2.3} \mathrm{~F}_{-} \mathrm{BF}_{4}$ or TFSA- $(\mathrm{FH})_{2.3} \mathrm{~F}$ ionic liquid mixture occurs sequentially, giving two stages in the curve at the temperature corresponding to the decomposition of $\mathrm{EMIm}(\mathrm{FH})_{2.3} \mathrm{~F}$ and that of $\mathrm{EMImBF}_{4}$ or
EMImTFSA. The $\mathrm{BF}_{4}$-TFSA system showed a gradual weight loss at and above the decomposition temperature of $\mathrm{EMImBF}_{4}$.

\section{4 Electrochemical stability}

Electrochemical stability was examined by cyclic voltammetry using a glassy carbon electrode at the scan rate of $5 \mathrm{mV} \mathrm{s}^{-1}$. Neat EMImBF 4 or EMImTFSI shows a similar electrochemical stability with the cathode limit of $-2.5 \mathrm{~V}$ vs. $\mathrm{Fc}^{+} / \mathrm{Fc}$ and anode limit of $+2.1 \mathrm{~V}$ vs. $\mathrm{Fc}^{+}$ /Fc. Mixing of these two RTILs do not change the electrochemical stability in any ratio. Cyclic voltammogram of EMIm $(\mathrm{FH})_{2.3} \mathrm{~F}-\mathrm{EMImBF}$ is shown in Fig. 3. The anode limit of neat $\operatorname{EMIm}(\mathrm{FH})_{2.3} \mathrm{~F}$ is $+1 \mathrm{~V}$ vs. $\mathrm{Fc}^{+} / \mathrm{Fc}$, which is probably ascribed to the oxidation of the cation accompanied by fluorination according to the previous study for neat liquids. ${ }^{8)}$ The reaction of the cathode limit is considered to be the reduction of $(\mathrm{HF})_{n} \mathrm{~F}^{-}$to give $\mathrm{H}_{2}$ evolution. Although the potential of $\mathrm{H}_{2}$ evolution depends on the electrode material, it is $-1.8 \mathrm{~V}$ vs. $\mathrm{Fc}^{+} / \mathrm{Fc}$ on a glassy carbon electrode. In the mixed RTILs, the currents at the anode and cathode limits observed for $\operatorname{EMIm}(\mathrm{FH})_{2.3} \mathrm{~F}$ are decreased with decrease in molar ratio of $(\mathrm{FH})_{n} \mathrm{~F}^{-}$, suggesting the involvement of $(\mathrm{FH})_{n} \mathrm{~F}^{-}$in both the limits. The cyclic voltammogram of the $\operatorname{EMIm}(\mathrm{FH})_{2.3} \mathrm{~F}$ EMImTFSI mixture is essentially the same as that of $\mathrm{EMIm}(\mathrm{FH})_{2.3} \mathrm{~F}-\mathrm{EMImBF}_{4}$, although the peak current density is slightly different.

\section{References}

1) T. Welton, Chem. Rev., 99, 2071 (1999).

2) K. R. Seddon, J. Chem. Technol. Biotechnol., 68, 351 (1997).

3) P. Wasserscheid and W. Kein, Angew. Chem. Int. Ed., 39, 3772 (2000).

4) R. Hagiwara, Electrochemistry, 70, 130 (2002).

5) J. S. Wilkes and M. J. Zaworotko, J. Chem. Soc., Chem. Commun., 1992, 965.

6) P. Bonhôte, A. -P. Dias, M. Armand, N. Papageorgiou, K. Kalyanasundaram, and M. Grätzel, Inorg. Chem., 35, 1168 (1996).

7) A. Noda, K. Hayamizu, and M. Watanabe, J. Phys. Chem. $B, \mathbf{1 0 5}, 4603$ (2001).

8) R. Hagiwara, K. Matsumoto, Y. Nakamori, T. Tsuda, Y. Ito, H. Matsumoto, and K. Momota, J. Electrochem. Soc., 150, D195 (2003).

9) K. Matsumoto, R. Hagiwara, and Y. Ito, Electrochem. Solid-State Lett., 7, E41 (2004).

10) R. Hagiwara, Y. Nakamori, K. Matsumoto, and Y. Ito, J. Phys. Chem. B, 109, 5445 (2005).

11) G. Annat, D. R. MacFarlane, and M. Forsyth, J. Phys. Chem. B, 111, 9018 (2007) and references therein.

12) Y. Saito, K. Hirai, K. Matsumoto, R. Hagiwara, and Y. Minamizaki, J. Phys. Chem. B, 109, 2942 (2005).

13) Every, A. G. Bishop, M. Forsyth, and D. R. MacFarlane, Electrochim. Acta, 45, 1279 (2000). 